\title{
A Comparison of Creatine and Thiamine Supplementation on Heart Rate Recovery and Blood Lactate Levels
}

\author{
Muhammad Danial ${ }^{1}$, Hari Setijono ${ }^{2}$, Nining Widyah Kusnanik ${ }^{2}$ \\ ${ }_{1}^{1}$ Postgraduate Program in Sports Science, Universitas Negeri Surabaya, Indonesia \\ ${ }_{2}^{2}$ Department of Sports Coaching, Faculty of Sport Sciences, Universitas Negeri Surabaya, Indonesia \\ Email: muhammaddanial16070946014@mhs.unesa.ac.id
}

\begin{abstract}
:
The purpose of the study was to compare the effect of creatine and thiamine supplementation on heart rate recovery (HRR) and blood lactate levels. Twelve male students comprised the two experimental (creatine and thiamine) groups of the study. The creatine group was supplemented with $0,3 \mathrm{~g}$ per weight, with $30 \mathrm{ml}$ of water per dose of creatine four times a day, at regular intervals during the day, for 6 consecutive days. The thiamine group received $10 \mathrm{mg}$ per weight just one time 30 minutes after a meal with $150 \mathrm{ml}$ of water at the last supplementation days. After the supplementation period, subjects completed the incremental treadmill after a dynamic warm-up that consisted of walking at $6 \mathrm{~km} / \mathrm{h}$ for 3 minutes. An initial treadmill speed started with $8,64 \mathrm{~km} / \mathrm{h}$ for two minutes at $0 \%$ gradient followed by an increase of $1,44 \mathrm{~km} / \mathrm{h}$ every $30 \mathrm{~s}$ until subjects reached their volitional exhaustion. After exercise cessation subjects continued with an active recovery of $10.08 \mathrm{~km} / \mathrm{h}$ for approximately 5 minutes. Heart rate (HR) was regularly assessed from the first 5 min of passive recovery. Blood lactate levels were measured in the 9th min of passive recovery. There were no statistically significant differences in heart rate recovery and blood lactate levels after supplementation, respectively $(P>0.05)$. Based on these results, it appears that creatine supplementation did not provide a different effect with thiamine on the recovery of heart rate and blood lactate levels.

Keywords:

heart rate recovery; blood lactate; creatine; thiamine; supplementation
\end{abstract}

\section{Introduction}

Recovery is an integral part of the overall training series (Beck, Thomson, Swift, \& von Hurst, 2015). In competitive sports, especially at the elite level, recovery becomes a very important component (Wheeler, 2013) because athletes can re-train faster and with better quality (Barnett, 2006) even with a high frequency of training (Barnett, 2006; Wheeler, 2013). On the other hand, inadequate recovery will have an impact on the psychological, physiological, emotional and social components of athletes which ultimately disrupt the athlete's appearance (Venter, 2014).

One of the physiological parameters known to be associated with recovery is lactic acid (Bonov, 1991; Buchheit, 2014; E. Fox, Bowers, \& Foss, 1993; Westerblad, Allen, \& Lännergren, 2006). Lactic acid is an anaerobic glycolysis product, where the concentration will increase with increasing exercise intensity (Ohkuwa et al., 2009). According to Kenney, Wilmore, \& Costill (2012) that lactic acid began to accumulate at a running speed of $12 \mathrm{~km}$ per hour using a treadmill. Increased blood lactic acid concentration is one of the causes of muscle fatigue (E. L. Fox, 1984). To restore high concentrations of lactic acid to normal concentrations $(\leq 2 \mathrm{mmol} /$ L) often requires a relatively slow time of approximately one to two hours (Bompa \& Carrera, 2015; Kenney et al., 2012), while athletes are required to quickly recover from training to attend the next training session. 
In addition to lactic acid, heart rate recovery is also a parameter of one's recovery or fitness (Bonov, 1991; E. Fox et al., 1993; Plews, Laursen, Stanley, Kilding, \& Buchheit, 2013; Westerblad et al., 2006). According to Benson \& Connolly (2011) that someone who is fit tends to have a lower resting heart rate. The mean value of heart rate in a trained subject is $50 \mathrm{bpm}$ while in an untrained subject is $70 \mathrm{bpm}$. A person's fitness can also be assessed through a steady-state heart rate. At the same workload, fitter individuals show lower steady-state than fewer fit individuals (Katch, McArdle, \& Katch, 2011).

To anticipate that athlete's performance does not decrease, athletes and trainers are advised to consider recovery modalities as an effort to restore the recovery components mentioned above (Sahraei, Khoshnam, \& Nikseresht, 2013). One of the recovery modalities is through supplementation (Halson, 2008). According to Moore (2015) that the provision of proper nutrition or supplements is very important for recovery after exercise.

Thiamine and creatine monohydrate are supplements that are often used in sports both to improve exercise performance and to speed recovery (Cooper, Naclerio, Allgrove, \& Jimenez, 2012; Dorrell, Gee, \& Middleton, 2016; Lanhers et al., 2015; Mehdi, Reza, Saba, \& Kamilia, 2013). However, the two supplements have different administration characteristics. Creatine in the loading phase is generally given for 5 to 7 days (Cooke, Rybalka, Williams, Cribb, \& Hayes, 2009; Dorrell et al., 2016) while thiamine is given only once, four hours before physical activity (Mehdi et al., 2013; Smithline, Donnino, \& Greenblatt, 2012). Because these two types of supplements have different administration characteristics. This study was conducted to compare the effects of creatine and thiamine supplementation on the heart rate recovery (HRR) and the blood lactate levels.

\section{Research Methods}

\subsection{Subjects}

Twelve male college students (age $=20.1 \pm 0.5 \mathrm{yr}$, height $=169.0 \pm 5.5 \mathrm{~cm}$, and body weight $=61.0 \pm 6.5 \mathrm{~kg}$ ), volunteered to take part in this study. All subjects were regularly involved in a team-sport competition such as football, volleyball or basketball. The subjects were performing their training for a period of at least two years. Subjects were informed about the procedure and purposes before enrolling in the study and signed an informed consent document. Prior to a familiarization session replicating the experimental procedure, all subjects were screened for medical history and legal ergogenic aids use. A comprehensive list of diet food products and medicines containing caffeine were provided to subjects prior to the first familiarization trial. Subjects abstained from all foods and liquids containing caffeine for 48-h before the experimental trials, as well as any alcohol. The investigation was approved by the head of sports science and fitness center of University Negeri Surabaya.

Table 1. Characteristics of Subjects

\begin{tabular}{lcc}
\hline Variables & Creatine $(\mathbf{n}=\mathbf{6})$ & Thiamine $(\mathbf{n}=\mathbf{6})$ \\
\hline Age $(\mathrm{yr})$ & $20.2 \pm 0.4$ & $20.0 \pm 0.6$ \\
Height $(\mathrm{cm})$ & $168.3 \pm 6.2$ & $169.8 \pm 5.4$ \\
Body weight $(\mathrm{kg})$ & $61.2 \pm 7.2$ & $60.8 \pm 6.3$ \\
BMI $\left(\mathrm{kg} / \mathrm{m}^{2}\right)$ & $18.1 \pm 1.7$ & $17.9 \pm 1.7$ \\
Resting heart rate $(\mathrm{bpm})$ & $69.8 \pm 3.3$ & $69.0 \pm 10.3$ \\
Maximum heart rate $(\mathrm{bpm})$ & $199.8 \pm 0.4$ & $195.3 \pm 10.9$ \\
Heart rate reserve $(\mathrm{bpm})$ & $130.0 \pm 3.3$ & $126.3 \pm 16.3$ \\
\hline
\end{tabular}




\subsection{Experimental Protocol}

Before formal measurements, all subjects visited the laboratory initially to ensure familiarity with the incremental treadmill test. Subjects were educated during the familiarization session by a well-trained fitness instructor. After the familiarization session, anthropometric indexes and the heart rate were measured and followed by a standard 6-day supplementation protocol of Creatine and Thiamine. After the supplementation period, subjects completed the second exercise-testing protocol after a dynamic warm-up that consisted of walking at $6 \mathrm{~km} / \mathrm{h}$ for 3 minutes. An initial treadmill speed started with $8,64 \mathrm{~km} / \mathrm{h}$ for two minutes at $0 \%$ gradient followed by an increase of $1,44 \mathrm{~km} / \mathrm{h}$ every $30 \mathrm{~s}$ until subjects reached their volitional exhaustion. After exercise cessation subjects continued with an active recovery of $10.08 \mathrm{~km} / \mathrm{h}$ for approximately 5 minutes (Machado, Kravchychyn, Peserico, da Silva, \& Mezzaroba, 2013; Mann, Webster, Lamberts, \& Lambert, 2014). Subjects then lie supine position as passive recovery (Barak et al., 2011). Heart rate (HR) was regularly assessed with a Polar H7 Bluetooth heart rate sensor (Polar Electro Inc, Finland) from the first 5 min of passive recovery. Blood lactate levels were measured in the 9th min of passive recovery with Accutrend ${ }^{\mathbb{B}}$ Plus (Roche) as previously described (Balducci et al., 2016; Kusnanik, Rahayu, \& Rattray, 2018).

\subsection{Supplementation protocol}

Subjects were divided into two groups: the creatine group (Creatine; $n=6$ ) was supplemented with $0,3 \mathrm{~g}$ per weight, with $30 \mathrm{~mL}$ of water per dose creatine four times a day, at regular intervals during the day, for 6 consecutive days. The thiamine group received $10 \mathrm{mg}$ per weight just one time 30 minutes after a meal with $150 \mathrm{ml}$ of water at the last supplementation day (Choi, Baek, \& Choi, 2013). The day after the final ingestion, all subjects letterally reported taking supplements as instructed for the entirety of the study.

\subsection{Statistical analyses}

All data were reported as means with their standard deviation. A Kruskal-Wallis was used to determine differences between heart rate recovery and blood lactate levels after supplementation. Data were analyzed by SPSS 22.0 software for Windows. The level of statistical significance was set at $\mathrm{p}<0.05$.

\section{Results and Discussion}

A total of 12 male students completed the study. The age, height, body weight, BMI, resting heart rate, maximum heart rate, and heart rate reserve are shown in Table 1 . There were no differences between the two groups with respect to these characteristics $(p>0.05)$. In addition, heart rate recovery in the $1^{\text {st }}, 2^{\text {nd }}, 3^{\text {rd }}, 4^{\text {th }}, 5^{\text {th }}$ minutes, and blood lactate of the study group are included in Figure 1 and figure 2.

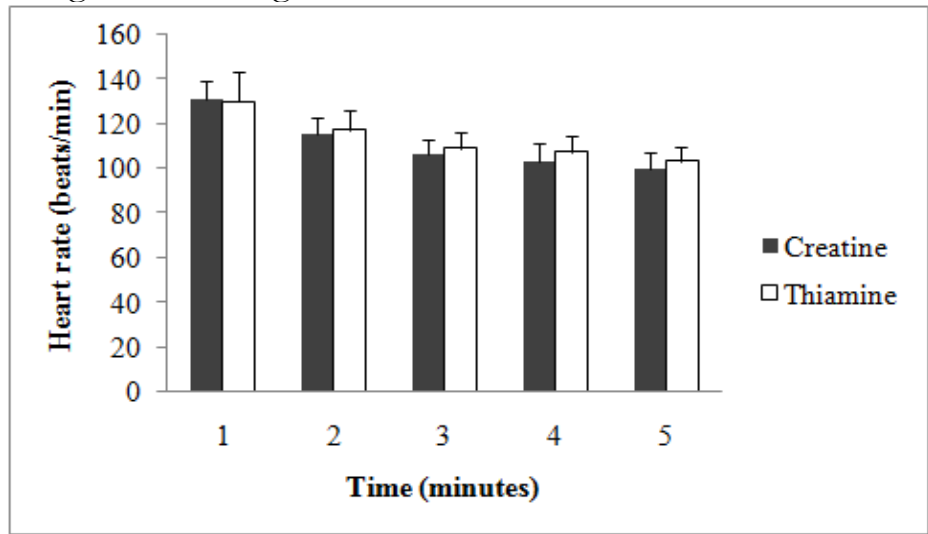

Figure 1. Heart rate responses of athletes during passive recovery after supplementation. 
Figure 1 shows heart rate responses during passive recovery. The mean value for heart rate in the $1^{\text {st }}$ minute of passive recovery was $131.5 \pm 7.5 \mathrm{bpm}$ (creatine) with a range of $123.6-139.4$ $\mathrm{bpm}$ and $130.0 \pm 13.1 \mathrm{bpm}$ (thiamine) with a range of $116.3-143.7 \mathrm{bpm}$. The mean value for heart rate in the $2^{\text {nd }}$ minute of passive recovery was $115.8 \pm 7.1 \mathrm{bpm}$ (creatine) with a range of 108.3 $-123.3 \mathrm{bpm}$ and $117.3 \pm 8.5 \mathrm{bpm}$ (thiamine) with a range of $108.3-126.3 \mathrm{bpm}$. The mean value for heart rate in the $3^{\text {rd }}$ minute of passive recovery was $106.8 \pm 6.3 \mathrm{bpm}$ (creatine) with a range of $100.3-113.4 \mathrm{bpm}$ and $109.3 \pm 7.3 \mathrm{bpm}$ (thiamine) with a range of $101.7-117.0 \mathrm{bpm}$. The mean value for heart rate in the $4^{\text {th }}$ minute of passive recovery was $103.5 \pm 7.8 \mathrm{bpm}$ (creatine) with a range of $95.3-111.7 \mathrm{bpm}$ and $107.3 \pm 7.3 \mathrm{bpm}$ (thiamine) with a range of $99.6-115.1 \mathrm{bpm}$. The mean value for heart rate in the $5^{\text {th }}$ minute of passive recovery was $99.8 \pm 8.0 \mathrm{bpm}$ (creatine) with a range of $91.5-108.2 \mathrm{bpm}$ and $103.7 \pm 5.9 \mathrm{bpm}$ (thiamine) with a range of $97.5-109.8 \mathrm{bpm}$.

This study showed that there was no significant difference in the recovery of heart rate after supplementation with both creatine and thiamine. Previous studies showed creatine and thiamine supplementation both contribute significantly to decreases in heart rate after exercise (Bautista-Hernández, López-Ascencio, Del Toro-Equihua, \& Vásquez, 2008; Sanchez-Gonzalez, Wieder, Kim, Vicil, \& Figueroa, 2011). However, in the present study, the mean values of heart rate recovery in the creatine group were only slightly lower than the thiamine group with a significance value of $\mathrm{p}>0.05$. The results of this study may be influenced by several factors: First of all, subjects did not get enough rest before following the test protocol so that it greatly affected the heart rate. Secondly, creatine and thiamine supplementation were not accompanied by a controlled exercise program.

Nevertheless, some literature also states that the effect of creatine supplementation on heart rate seems to be more significant during exercise than during recovery (Dalbo, Roberts, Stout, \& Kerksick, 2008; Kilduff et al., 2004). The study was supported by the research of Manna \& Khanna (2016) who examined the effect of creatine supplementation on cardiovascular adaptation and endurance performance of athletes. A total of 60 male athletes involved in the study with the age range of 16-19 years were randomly selected in the group, the experimental group $=30$ people were given 5 grams of creatine per day for 4 weeks. The results showed a significant decrease in heart rate in the experimental group during sub-maximal exercise when compared with the control group. However, observations on heart rate recovery did not show a significant difference.

As for the effect of thiamine supplementation on heart rate recovery, Bautista-Hernández, López-Ascencio, Del Toro-Equihua, \& Vásquez (2008) conducted research on 27 athletes. Athletes were given thiamine $1 \mathrm{mg}$ per $\mathrm{kg}$ of body weight. The results showed a decrease in heart rate followed by an increase in oxygen consumption. The possibility of thiamine supplementation could increase the ability of muscles to extract oxygen from arterial blood, which was a major factor in an organism's capacity for oxygen consumption.

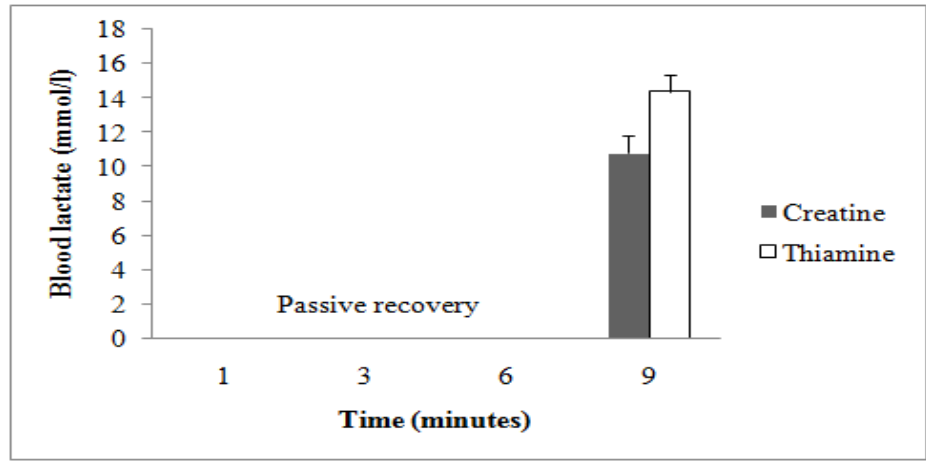

Figure 2. Blood lactate concentration of athletes during passive recovery after supplementation. The data represent the mean $\pm S D$. 
The mean value for blood lactate concentration as shown in figure 2 was $10.8 \pm 2.3$ $\mathrm{mmol} / \mathrm{l}$ (creatine) with a range of $8.4-13.2 \mathrm{mmol} / \mathrm{l}$ and $14.4 \pm 5.0 \mathrm{mmol} / \mathrm{l}$ (thiamine) with a range of $9.2-19.6 \mathrm{mmol} / \mathrm{l}$. This study showed that the blood lactate levels were lower in the creatine group than in the thiamine group after supplementation. However, these findings were not statistically significant. Previous studies on the effect of creatine supplementation on blood lactate indeed showed controversial results (Oliver, Joubert, Martin, \& Crouse, 2013; Stroud et al., 1994).

In some of the literature mentioned that the administration of creatine increases the proportion of glucose to be oxidized so that energy production in muscle cells also increases. Thus the concentration of lactate in skeletal muscle cells decreases. The ability of creatine to phosphorylate and activate AMP-activated protein kinase (AMPK) may be responsible for this effect. Another report states that AMPK activation plays an important role in increasing glucose uptake in muscles that are contracting (Koistinen \& Zierath, 2002).

In theory, the administration of creatine increases phosphocreatine ( $\mathrm{PCr}$ ) stores (Bird, 2003). This increase in PCr concentration causes an increase in the ability to produce energy during exercise (explosive and high intensity) and increases the ability to recover from intensive training. Cramer et al. (2000) add that increasing the concentration of PCr might inhibit the production of hydrogen ions and other anaerobic processes during the breakdown of adenosine triphosphate (ATP). Thus PCr can contribute to maintaining optimal $\mathrm{pH}$ levels in the muscles so as to enable training activities to continue with minimal fatigue.

As creatine, like creatine, thiamine also has a function as an anti-fatigue reagent that thiamine can inhibit the production of lactic acid through increased activity of PDH (Masuda, Masuda, \& Hatta, 2015). PDH is a mitochondrial enzyme that functions to oxidize carbohydrates to produce ATP. However, a lack of thiamine in the blood will have an impact on increasing lactic acid accumulation by approximately 7\%. The lack of thiamine concentration causes a decrease in PDH activity so that carbohydrate oxidation also decreases (Beek, Dokkum, Wedel, Schrijver, \& Berg, 1994; Masuda et al., 2015).

\section{Conclusion}

In conclusion, this study suggested that creatine supplementation did not provide a different effect with thiamine on heart rate recovery and blood lactate levels. Further research is needed to include programmed exercise and a longer duration of supplementation.

\section{Acknowledgment}

The author wishes to acknowledge the Rector of Universitas Negeri Surabaya.

\section{References}

Balducci, P., Clémençon, M., Morel, B., Quiniou, G., Saboul, D., \& Hautier, C. A. (2016). Comparison of level and graded treadmill tests to evaluate endurance mountain runners. Journal of Sports Science and Medicine.

Barak, O. F., Ovcin, Z. B., Jakovljevic, D. G., Lozanov-Crvenkovic, Z., Brodie, D. a, \& Grujic, N. G. (2011). Heart rate recovery after submaximal exercise in four different recovery protocols in male athletes and non-athletes. Journal of Sports Science \& Medicine, 10(2), 369375. 
Barnett, A. (2006). Using recovery modalities between training sessions in elite athletes: Does it help? Sports Medicine, 36(9), 781-796.

Bautista-Hernández, V. M., López-Ascencio, R., Del Toro-Equihua, M., \& Vásquez, C. (2008). Effect of thiamine pyrophosphate on levels of serum lactate, maximum oxygen consumption and heart rate in athletes performing aerobic activity. Journal of International Medical Research, 36(6), 1220-1226.

Beck, K., Thomson, J. S., Swift, R. J., \& von Hurst, P. R. (2015). Role of nutrition in performance enhancement and postexercise recovery. Open Access Journal of Sports Medicine, 259.

Beek, E. J. V. Der, Dokkum, W. Van, Wedel, M., Schrijver, J., \& Berg, H. Van Den. (1994). Thiamin, riboflavin and vitamin b6: Impact of restricted intake on physical performance in man. Journal of the American College of Nutrition, 13(6), 629-640.

Benson, R., \& Connolly, D. (2011). Heart rate training.

Bird, S. P. (2003). Creatine supplementation and exercise performance: A brief review. Journal of Sports Science and Medicine, 2(4), 123-132.

Bompa, T. O., \& Carrera, M. C. (2015). Periodization Training For Sports. (E. Evans, Ed.) (3rd ed.). United States of America: Human Kinetics.

Bonov, P. (1991). Study of the relationship between speed, heart rate and the accumulation of lactic acid in the blood, 54-57.

Buchheit, M. (2014). Monitoring training status with HR measures: Do all roads lead to Rome? Frontiers in Physiology.

Choi, S.-K., Baek, S.-H., \& Choi, S.-W. (2013). The effects of endurance training and thiamine supplementation on anti-fatigue during exercise. Journal of Exercise Nutrition and Biochemistry, 17(4), 189-198.

Cooke, M. B., Rybalka, E., Williams, A. D., Cribb, P. J., \& Hayes, A. (2009). Creatine supplementation enhances muscle force recovery after eccentrically-induced muscle damage in healthy individuals. Journal of the International Society of Sports Nutrition, 6, 1-11.

Cooper, R., Naclerio, F., Allgrove, J., \& Jimenez, A. (2012). Creatine supplementation with specific view to exercise/sports performance: An update. Journal of the International Society of Sports Nutrition (Vol. 9).

Cramer, J., Eckerson, J., Perry, S., Moore, G., Ebersole, K., Stout, J., ... Bull, A. (2000). Effect of creatine loading on neuromuscular fatigue threshold. Journal of Applied Physiology, 88(1), 109-112.

Dalbo, V. J., Roberts, M. D., Stout, J. R., \& Kerksick, C. M. (2008). Putting to rest the myth of creatine supplementation leading to muscle cramps and dehydration. British Journal of Sports Medicine.

Dorrell, H. F., Gee, T. I., \& Middleton, G. (2016). An update on effects of creatine supplementation on performance: A review. Sports Nutrition and Therapy, 1(1).

Fox, E., Bowers, R., \& Foss, M. (1993). The physiological basis for exercise and sport. Dubuque: Brown \& Benchmark.

Fox, E. L. (1984). Sport Physiology (2nd ed.). Japan: CBS College Publishing.

Halson, S. L. (2008). Nutrition, sleep, and recovery. European Journal of Sport Science, 8(2), 119-126.

Katch, V. L., McArdle, W. D., \& Katch, F. I. (2011). Essentials exercise physiology. (E. Lupash, Ed.) (4th ed.). China: Lippincott Williams.

Kenney, W. L., Wilmore, J. H., \& Costill, D. L. (2012). Physiology of sport and exercise (5th ed.). United States of America: Human Kinetics.

Kilduff, L. P., Georgiades, E., James, N., Minnion, R. H., Mitchell, M., Kingsmore, D., ... Pitsiladis, Y. P. (2004). The effects of creatine supplementation on cardiovascular, metabolic, and thermoregulatory responses during exercise in the heat in endurance-trained humans. International Journal of Sport Nutrition and Exercise Metabolism, 14(4), 443-460.

Koistinen, H. A., \& Zierath, J. R. (2002). Regulation of glucose transport in human skeletal muscle. Annals of Medicine, 34(6), 410-418.

Kusnanik, N. W., Rahayu, Y. S., \& Rattray, B. (2018). Physiological Demands of Playing Field 
Hockey Game at Sub Elite Players. IOP Conference Series: Materials Science and Engineering, 288(1).

Lanhers, C., Pereira, B., Naughton, G., Trousselard, M., Lesage, F. X., \& Dutheil, F. (2015). Creatine Supplementation and Lower Limb Strength Performance: A Systematic Review and Meta-Analyses. Sports Medicine, 45(9), 1285-1294.

Machado, F. A., Kravchychyn, A. C. P., Peserico, C. S., da Silva, D. F., \& Mezzaroba, P. V. (2013). Incremental test design, peak "aerobic" running speed and endurance performance in runners. Journal of Science and Medicine in Sport, 16(6), 577-582.

Mann, T. N., Webster, C., Lamberts, R. P., \& Lambert, M. I. (2014). Effect of exercise intensity on post-exercise oxygen consumption and heart rate recovery. European Journal of Applied Physiology, 114(9), 1809-1820.

Manna, I., \& Khanna, G. L. (2016). Supplementary Effect of Creatine on Cardiovascular Adaptation and Endurance Performance in Athletes. Sports Nutrition and Therapy, 1(1), 1-5.

Masuda, H., Masuda, T., \& Hatta, H. (2015). Effect of thiamin (vitamin B B $_{\text {) }}$ on carbohydrate metabolism at rest and during exercise. The Journal of Physical Fitness and Sports Medicine, 4(4), 337-341.

Mehdi, K., Reza, K., Saba, M., \& Kamilia, M. (2013). Effect of supplementary consumption vitamin $\mathrm{B} 1$ (thiamine) on blood glucose changes during and after maximal aerobic exercise. International Journal of Biosciences, 3(7), 195-201.

Moore, D. R. (2015). Nutrition to Support Recovery from Endurance Exercise: Optimal Carbohydrate and Protein Replacement. Current Sports Medicine Reports, 14(4), 294-300.

Ohkuwa, T., Tsukamoto, K., Yamai, K., Itoh, H., Yamazaki, Y., \& Tsuda, T. (2009). The relationship between exercise intensity and lactate concentration on the skin surface. International Journal of Biomedical Science, 5(1), 23-27.

Oliver, J. M., Joubert, D. P., Martin, S. E., \& Crouse, S. F. (2013). Oral creatine supplementation's decrease of blood lactate during exhaustive, incremental cycling. International Journal of Sport Nutrition and Exercise Metabolism, 23(3), 252-258.

Plews, D. J., Laursen, P. B., Stanley, J., Kilding, A. E., \& Buchheit, M. (2013). Training adaptation and heart rate variability in elite endurance athletes: Opening the door to effective monitoring. Sports Medicine.

Sahraei, F., Khoshnam, E., \& Nikseresht, A. (2013). Effect of active and passive recovery on blood pressure and heart rate in male athletes. European Journal of Experimental Biology, 3(6), 335-338.

Sanchez-Gonzalez, M. A., Wieder, R., Kim, J. S., Vicil, F., \& Figueroa, A. (2011). Creatine supplementation attenuates hemodynamic and arterial stiffness responses following an acute bout of isokinetic exercise. European Journal of Applied Physiology.

Smithline, H. A., Donnino, M., \& Greenblatt, D. J. (2012). Pharmacokinetics of high-dose oral thiamine hydrochloride in healthy subjects. BMC Clinical Pharmacology, 12(4).

Stroud, M. a, Holliman, D., Bell, D., Green, a L., Macdonald, I. a, \& Greenhaff, P. L. (1994). Effect of oral creatine supplementation on respiratory gas exchange and blood lactate accumulation during steady-state incremental treadmill exercise and recovery in man. Clinical Science (London, England: 1979), 87(6), 707-710.

Venter, R. E. (2014). Perceptions of team athletes on the importance of recovery modalities. European Journal of Sport Science, 14(SUPPL.1), 37-41.

Westerblad, H., Allen, D. G., \& Lännergren, J. (2006). Muscle Fatigue : Lactic Acid or Inorganic Phos- phate the Major Cause ? News in Physiological Science, 17(February 2002), 17-21.

Wheeler, K. B. (2013). Optimal recovery after exercise: nutrient timing. Retrieved February 19, 2018, from http://www.ideafit.com/fitness-library/optimal-recovery-after-exercisenutritent-timingby-keith-b-wheeler-phd-facsm. 